\title{
EKSTRAKSI CIRI SINYAL EEG UNTUK GANGGUAN PENYAKIT EPILEPSI MENGGUNAKAN TEKNIK SAMPLING
}

\author{
Siti Nur Azizatul Hasanah ${ }^{1)}$, Hindarto Hindarto ${ }^{2)}$ \\ 1) Program Studi Teknik Informatika, Fakultas Teknik, \\ Universitas Muhammadiyah Sidoarjo \\ Jl. Raya Gelam No. 250 Candi Sidoarjo 61271 \\ E-mail : sitinurazizah305@gmail.com ${ }^{1)}$, hindarto@umsida.ac.id ${ }^{2)}$
}

\begin{abstract}
Abstrak
Epilepsi memiliiki gejala yang menyerupai gangguan histeria yaitu hilangnya kesadaran dan kontrol terhadap anggota tubuh. Sinyal EEG pada serangan epilepsi memiliki pola karakteristik yang memungkinkan professional kesehatan untuk membedakannya dari kondisi normal. Masalah lain yang muncul adalah kurangnya perbedaan yang jelas pada sinyal EEG antara serangan epilepsi dan non epilepsi. Penelitian ini bertujuan untuk mengekstrasi ciri sinyal EEG menggunakan metode teknik sampling. Penelitian ini menggunakan metode Teknik Sampling dan Backpropogation sebagai klasifikasinya.. Pada tahap pelatihan (training) menggunakan 80 data set dari masingmasing Set A dan Set E, data sen ini diambil dari Departemen Epileptology, University of Bonn, Sigmund FreudStrasse 25, 53105Bonn - Jerman. Sedangkan pada tahap pengujian (testing) menggunakan 100 data set. Penelitian ini menggunakan metode back- propagation (20-40-2) yaitu 2 input sinyal EEG, satu hidden layer dengan 20 unit dan dua target epilepsi dan non epilepsi . Dari pengujian data tersebut didapat nilai akurasi sebesar $100 \%$.
\end{abstract}

Kata kunci: Teknik Sampling, Backpropagation, Sinyal EEG.

\begin{abstract}
Epilepsy has symptoms resembling a disorder of hysteria that is the loss of awareness and control over the members of the body. EEG signals epilepsy attacks have characteristics that allow health professionals of distinguish it from normal conditions. Another problem that emerged was the lack of a clear distinction between EEG signals epilepsy seizures and non epilepsy. This research aims to characterize the EEG signal using extraction method of sampling. This research using the method of sampling techniques and Backpropogation as its classification. At this stage of training ( training) users data sets from the 80 each set A and set E, sen was taken from Departement of Epileptology, University of Bonn, Sigmund Freud - Strasse 25, 53105 Bonn- Germany. While in testing phase (testing) using 100 data sets. This research method using Backpropogation ( 20-40-2 ) i.e EEG signal input 2, one hidden layer with 20 units and 2 epilepsy and non epilepsy target. The data obtained from testing of the accuracy value of $100 \%$
\end{abstract}

Key words: Sampling Techniques, Backpropogation, EEG Signals,

\section{Pendahuluan}

Epilepsi memiliiki gejala yang menyerupai gangguan hysteria yaitu hilangnya kesadaran dan kontrol terhadap anggota tubuh. Epiepsi merupakan gangguan yang terjadi karena adanya fungsi ketidak normalan seluruh atau sebagian otak yang dapat dilihat melalui pemeriksaan Elektro Ensefalo Grafy (EEG) atau Magnetic Resonance Imaging (MRI). Sedangkan pada penderita hysteria tidak ditemukan adanya gangguan fisik yang dapat menjelaskan gejala-gejala tersebut dan terdapat bukti adanya penyebab secara psikologis dalam bentuk hubungan kurun waktu yang jelas dengan masalah-masalah atau kejadian yang menimbulkan stress atau hubungan interpersonal yang terganggu (PPGDJIII,2002.h 81) Anonym (2002).
Sinyal EEG pada serangan epilepsi memiliki pola karakteristik yang memungkinkan professional kesehatan untuk membedakannya dari kondisi normal. Tetapi analisis secara visual tidak mungkin dilakukan secara rutin, karena sinyal EEG yang dihasilkan dari sistem monitoring EEG sangat besar dan cukup memakan waktu. Masalah lain yang muncul adalah kurangnya perbedaan yang jelas pada sinyal EEG antara serangan epilepsi dan non epilepsi.

Dalam penelitian ini metode yang digunakan adalah menggunakan Teknik Sampling pada jaringan saraf tiruan. Langkah pertama menggunakan teknik sampling untuk mengubah / ekstraksi sebuah sinyal menjadi komponen frekuensi dasarnya sehingga dipeorolehkan beberapa fitur untuk menangkap karakteristik spesifik dari EEG 
sinyal untuk mendapatkan klasifikasi terdeteksi epilepsi atau non epilepsi.

Penelitian ini memiliki tujuan untuk mengekstrasi ciri sinyal EEG menggunakan metode teknik sampling dan untuk menghasilkan perangkat lunak yang mampu melakukan ekstrasi ciri sinyal EEG pada penyakit epilepsi dengan menggunakan metode teknik sampling.

\section{Penelitian Terkait}

Bagian ini menjelaskan metode various Features, bahwa epilepsi adalah gangguan kronis atau penyakit yang ditandai oleh kejang-kejang dan mempengaruhi orang-orang disegala usia. Epilepsi biasanya hanya di diagnosis seseorang setelah lebih dari satu kejang. Karena aktifitas sel saraf diotak menjadi terganggu, menyebabkan orang tersebut memiliki perilaku yang tidak biasa. Sehingga diperlukan untuk mendeteksi kejang dan mencapai penghentian kejang. Electroencephalogram (EEG) sinyal teknik pengolahan digunakan dalam deteksi kejang epilepsi. EEG ini paling berguna dan salah satu tes diagnostic utama untuk studi epilepsi Ratnaprabaha, et al (2014).

Sinyal Elektrode Enchepalo Graph Untuk Menggerakkan Kursor Menggunakan Teknik Sampling Dan Jaringan Syaraf Tiruan. Klasifikasi menggunakan aplikasi dari jaringan syaraf tiruan propagasi balik (backpopagation) dan untuk ekstraksi fitur dari sinyal Electro Encephalo Graph (EEG) menggunakan Teknik Sampling (TS). Bertujuan untuk mengembangkan suatu sistem yang bisa digunakan untuk menggerakkan kursor dari pengenalan sinyal EEG Hindarto \& Hariadi (2011).

\section{METODE TEKNIK SAMPLING}

Teknik sampling adalah merupakan teknik pengambilan sampel. Untuk menentukan sampel dalam penelitian, terdapat berbagai teknik sampling yang digunakan. Teknik sampling pada dasarnya dikelompokkan menjadi dua yaitu Propabily Sampling dan Nonprobabily Sampling.

Pada penelitian ini menggunakan metode teknik simple random sampling. Metode tersebut digunakan untuk mengekstraksi ciri sinyal EEG untuk Epilepsi. Simple Random Sampling (SRS) digunakna untuk melakukan proses ekstraksi sinyal EEG dengan mencari nilai minimum, maximum, median dan standart deviasi yang sebelumnya sinyal telah dibagi menjadi beberapa subsinyal terlebih dahulu.

Data set yang digunakan data set A dan set E. Sesuai dengan referensi yang ada, semua sinyal EEG direkam dengan sistem amplifier dengan kanal 128. Digitalisasi data dengan frekuensi 173,61 sampel per detik menggunakan $A / D$ converter 12 bit. Band passfilter diatur pada $0,5340 \mathrm{~Hz}(12 \mathrm{~dB} /$ oct $)$. Masing-masing data sinyal EEG digital tersebut terdiri atas 4097 data diskrit. Plot potongan sinyal EEG set A dan set $E$ yang digunakan dalam penelitian ini dalam bentuk time series ${ }^{[4]}$.

\section{FLOWCHART PROGRAM EKSTRAKSI CIRI}

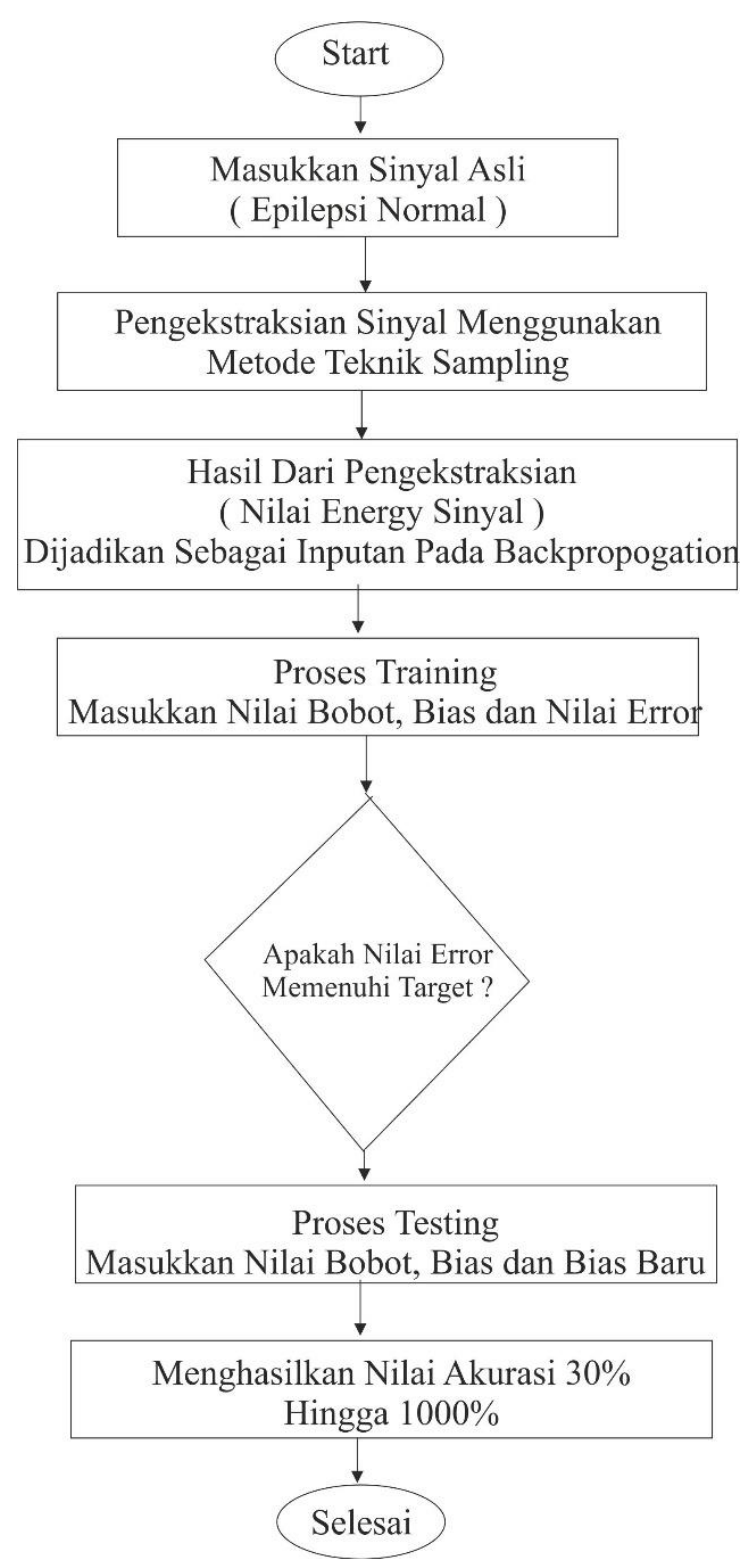

Gambar 1.Flowchart Program Ekstraksi Ciri 


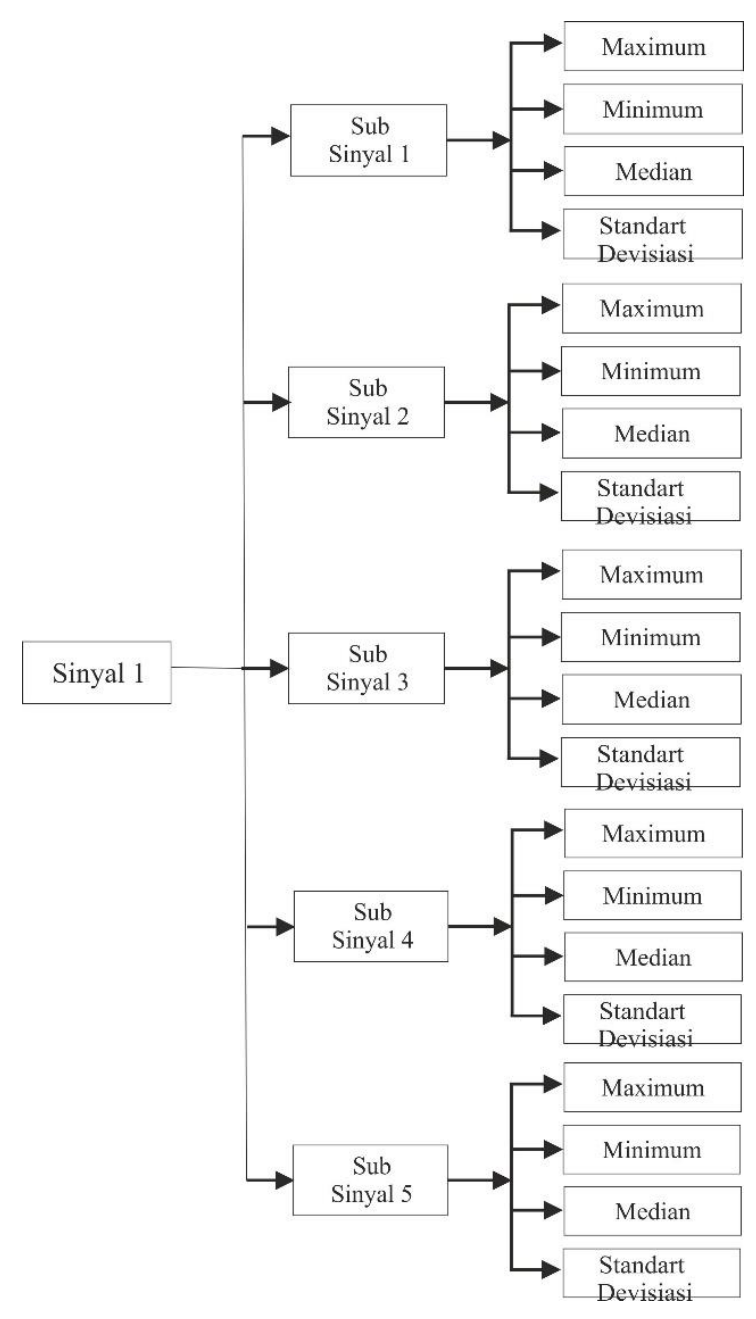

Gambar 2. Metode Teknik sampling

(a) Sample Sinyal, (b) Sample Sub Sinyal, (c)Seleksi Fitur

\section{Klasifikasi dengan Jaringan Syaraf Backpropagation}

Pada proses klasifikasi, identifikasi sinyal EEG diproses menggunakan backpropagation seperti ditunjukkan pada Gambar 3 Proses ini dilakukan setelah ekstraksi ciri sinyal EEG dengan teknik sampling. Hasil ekstraksi ciri digunakan sabagai nilai input, pada penelitian ini menggunakan metode back propagation (2-40-2) yaitu 20 unit yang berasal dari ekstraksi ciri sinyal EEG, satu hidden layer denga 20 unit dan satu target ( epilepsi dan non epilepsi).

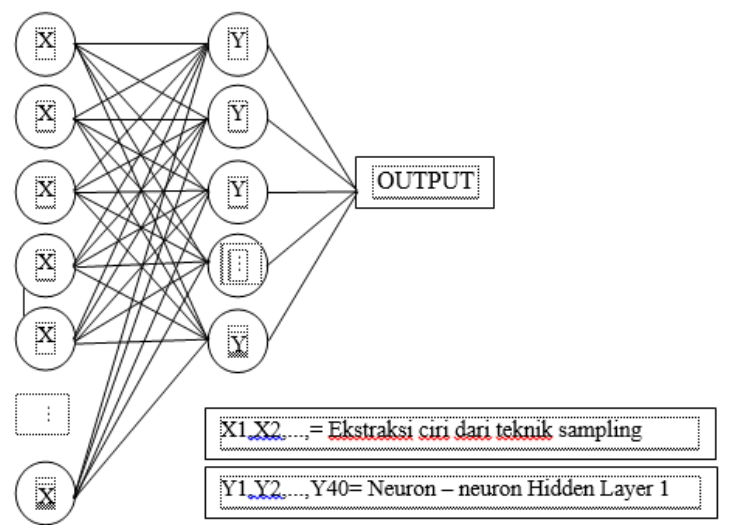

Gambar 3. Arsitektur jaringan Back Propagation Satu Hidden Layer

Proses klasifikasi terdiri dari dua tahap, pertama proses pembelajaran atau training. Kedua proses mapping atau proses pengujian/testing. Proses training yaitu dengan mencari nilai bobot terbaik dengan perolehan nilai error terkecil dari target keluaran yang diinginkan. Pada algoritma backpropagation untuk mengubah nilai bobot menggunakan error output dengan arah mundur (backward). Sebelumnya harus melakukan tahap perambatan maju (fordward) untuk mendapatkan nilai error, neuron - neuron akan diaktifkan dengan menggunakan fungsi aktivasi sigmaoid. Apabila keluaran backword pada lapisan tersembunyi (hidden layer) tidak sama dengan keluaran yang diinginkan, maka akan diteruskan kedalam lapisan masukan (input layer). Pada algoritma backpropagation nilai error dapat diminimalkan dengan menggunakan persamaan berikut :

$$
=\sum_{l=1}^{n} \sum_{k=1}^{r}\left(d_{l k}-o_{l k}\right)^{2}
$$

Dengan:

$$
\begin{array}{ll}
\mathrm{n} & =\text { jumlah dari sample data } \\
\mathrm{dlk} & =\text { nilai output yang ditargetkan } \\
\mathrm{Olk} & =\text { nilai output keluaran aktual }
\end{array}
$$

\section{Hasil dan Pembahasan}

Implementasi sistem pada penelitian ini halaman utama dari program yang berisi beberapa tombol untuk melakukan proses, axes untuk menampilkan sinyal EEG sebelum dan sesudah diekstaksi, tabel untuk menampilkan data dan edit untuk menampilkan data. Tombol upload digunakan untuk melakukan proses menampilkan sinyal EEG, tombol ekstraksi untuk melakukan proses ekstraksi sinyal EEG,tombol training untuk melakukan proses training, dan tombol testing untuk melakukan proses testing. 


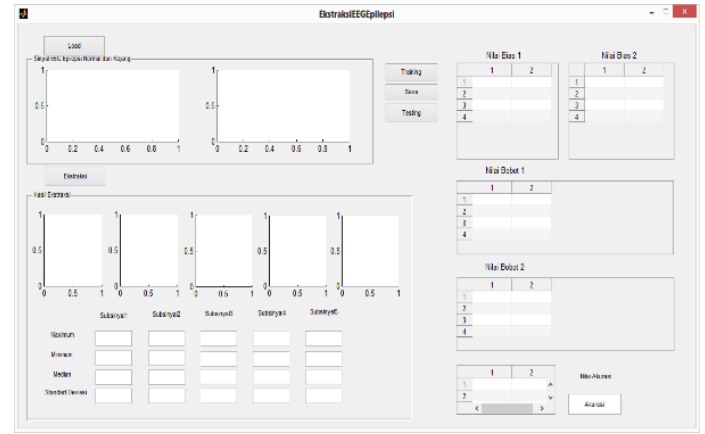

Gambar 4. Tampilan Utama Program

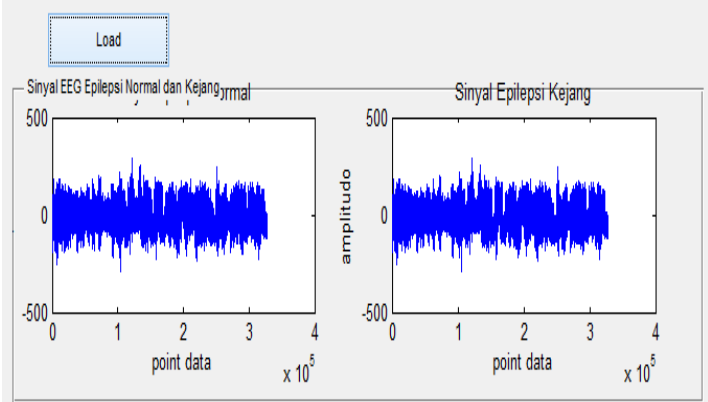

Gambar 5. Tombol Load sinyal dan Tampilan Sinyal

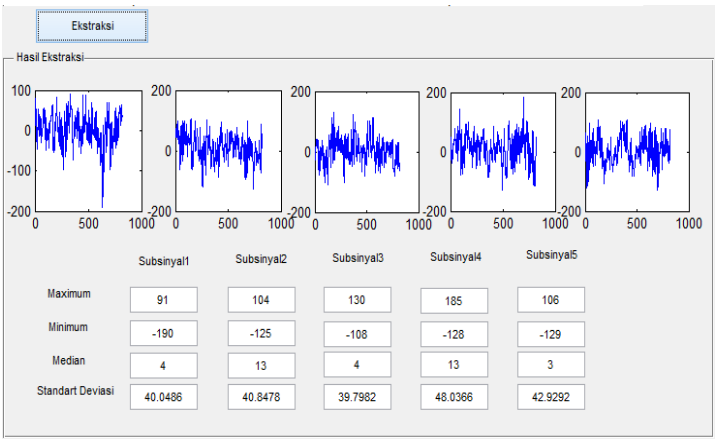

Gambar 6. Gambar Push Button Ekstraksi (menampilkan sinyal EEG setelah dibagi menjadi lima subsinyal)

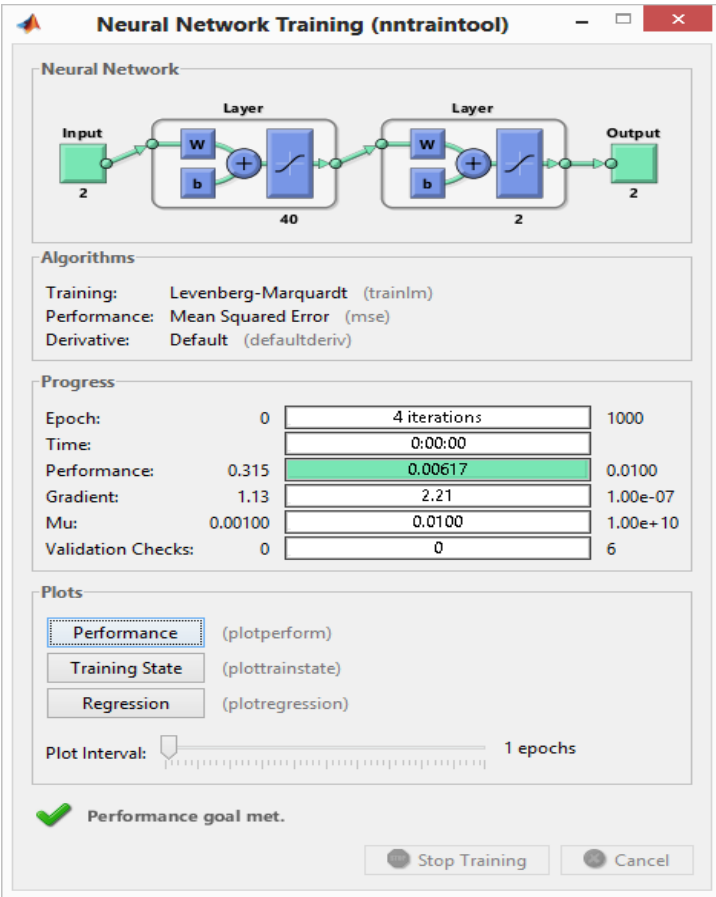

Gambar 7. Proses Training Backpropagation

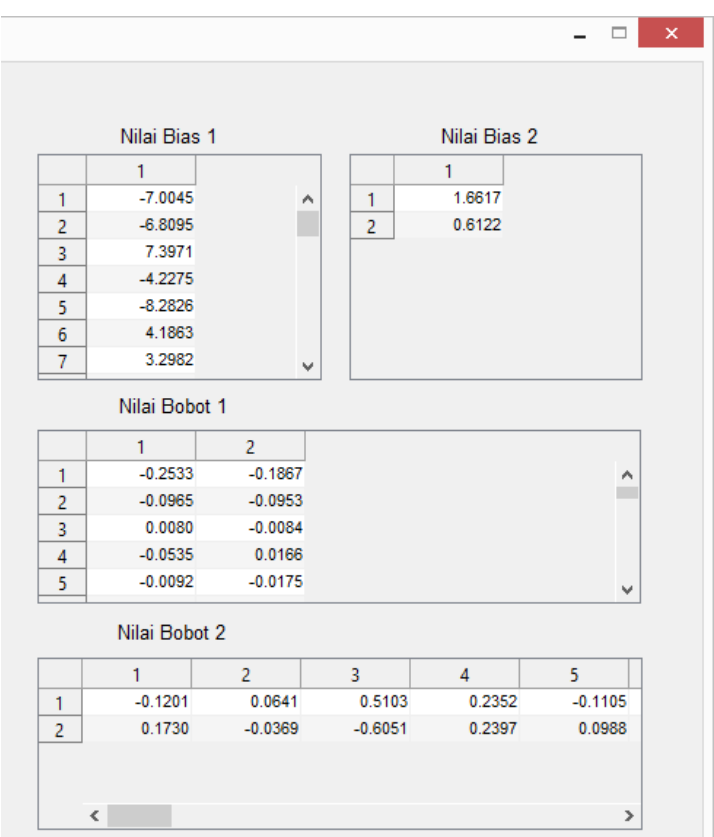

Gambar 8. Gambar Hasil Nilai Bias Dan Bobot

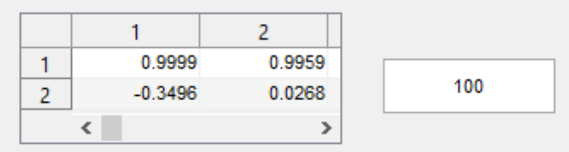

Gambar 9. Nilai Keluaran Tahap Testing dan Nilai Akurasinya 


\section{Hasil Pengujian}

Dalam penelitian ini lebih menekankan pada identifikasi sinyal EEG dengan menganalisis sinyal EEG menggunakan teknik sampling, selanjutnya hasil ekstraksi fitur akan masuk ke proses pembejaran dan pengujian menggunakan jaringan syaraf tiruan backpropagation. Untuk proses ektraksi sinyal EEG akan dipilah - pilah menurut kelasnya, yaitu epilepsy normal dan epilepsy tidak normal menjadi lima sub sinyal. Setiap sub sinyal akan dicari nilai minimun, nilai maksimum, nilai median, nilai standart daviasi. Data ini akan menjadi ciri dari sinyal EEG. Tabel 4.1. adalah hasil ekstraksi ciri sinyal EEG.

Berdasarkan tabel 2. output yang ditargetkan sesuai dengan output aktual, dimana pada tabel 4.2. output aktual menunnjukkan nilai interval antara 0,9818 sampai 1 membuktikan nilai keluaran aktual untuk kelas gerakan tangan kiri sesuai dengan nilai keluaran target yaitu 1. Sedangkan pada tabel 4.2. keluaran aktual kelas gerakan tangan kanan menunjukkan nilai interval antara -1 sampai - 0,9116 yang membuktikan nilai keluaran aktual sesuai dengan nilai keluaran yang ditargetkan yaitu -1 . Dengan demikian metode backpropagation (2-40-2) dapat melakukan klasifikasi dengan tepat dan nilai akurasi mencapai $100 \%$.

Tabel 4.1. Hasil Taknik Sampling dengan Mengambil Nilai Maximum, Minimum, Median, Standart Daviasi

\begin{tabular}{|c|c|c|c|c|}
\hline \multicolumn{5}{|c|}{ Sub Sinyal 1} \\
\hline & $\begin{array}{l}\text { Maxi } \\
\text { mum } \\
(\mathrm{Hz})\end{array}$ & $\begin{array}{l}\text { Mini } \\
\text { mum } \\
(\mathrm{Hz})\end{array}$ & $\begin{array}{l}\text { Medi } \\
\text { an } \\
(\mathrm{Hz})\end{array}$ & $\begin{array}{c}\text { Standart } \\
\text { Devisiasi } \\
(\mathrm{Hz})\end{array}$ \\
\hline $\begin{array}{l}\text { Epilepsi } \\
\text { Normal }\end{array}$ & 885 & -1550 & 177 & 424.4239 \\
\hline $\begin{array}{l}\text { Epilepsi } \\
\text { Tidak } \\
\text { Normal } \\
\text { (Kejang) }\end{array}$ & 91 & -190 & 4 & 40.0486 \\
\hline \multicolumn{5}{|c|}{ Sub Sinyal 2} \\
\hline & $\begin{array}{l}\text { Maxi } \\
\text { mum } \\
(\mathrm{Hz})\end{array}$ & $\begin{array}{l}\text { Mini } \\
\text { mum } \\
(\mathrm{Hz})\end{array}$ & $\begin{array}{l}\text { Medi } \\
\text { an } \\
(\mathrm{Hz})\end{array}$ & $\begin{array}{c}\text { Standart } \\
\text { Devisiasi } \\
(\mathrm{Hz})\end{array}$ \\
\hline $\begin{array}{l}\text { Epilepsi } \\
\text { Normal }\end{array}$ & 930 & -1625 & 181 & 505.8552 \\
\hline
\end{tabular}

\begin{tabular}{|c|c|c|c|c|}
\hline $\begin{array}{l}\text { Epilepsi } \\
\text { Tidak } \\
\text { Normal } \\
\text { (Kejang) }\end{array}$ & 104 & -125 & 13 & 40.8478 \\
\hline \multicolumn{5}{|c|}{ Sub Sinyal 3} \\
\hline & $\begin{array}{c}\text { Maxi } \\
\text { mum } \\
(\mathrm{Hz})\end{array}$ & $\begin{array}{c}\text { Mini } \\
\text { mum } \\
(\mathrm{Hz})\end{array}$ & $\begin{array}{c}\text { Medi } \\
\text { an } \\
(\mathrm{Hz})\end{array}$ & $\begin{array}{c}\text { Standart } \\
\text { Devisiasi } \\
(\mathrm{Hz})\end{array}$ \\
\hline $\begin{array}{l}\text { Epilepsi } \\
\text { Normal }\end{array}$ & 818 & -1761 & 167 & 459.1883 \\
\hline $\begin{array}{l}\text { Epilepsi } \\
\text { Tidak } \\
\text { Normal } \\
\text { (Kejang) }\end{array}$ & 130 & -108 & 4 & 39.7982 \\
\hline \multicolumn{5}{|c|}{ Sub Sinyal 4} \\
\hline & $\begin{array}{c}\text { Maxi } \\
\text { mum } \\
(\mathrm{Hz})\end{array}$ & $\begin{array}{c}\text { Mini } \\
\text { mum } \\
(\mathrm{Hz})\end{array}$ & $\begin{array}{c}\text { Medi } \\
\text { an } \\
(\mathrm{Hz})\end{array}$ & $\begin{array}{c}\text { Standart } \\
\text { Devisiasi } \\
(\mathrm{Hz})\end{array}$ \\
\hline $\begin{array}{l}\text { Epilepsi } \\
\text { Normal }\end{array}$ & 1027 & -1564 & 208 & 468.7927 \\
\hline $\begin{array}{l}\text { Epilepsi } \\
\text { Tidak } \\
\text { Norml } \\
\text { (Kejang) }\end{array}$ & 185 & -128 & 13 & 48.0366 \\
\hline \multicolumn{5}{|c|}{ Sub Sinyal 5} \\
\hline & $\begin{array}{c}\text { Maxi } \\
\text { mum } \\
(\mathrm{Hz})\end{array}$ & $\begin{array}{c}\text { Mini } \\
\text { mum } \\
(\mathrm{Hz})\end{array}$ & $\begin{array}{c}\text { Medi } \\
\text { an } \\
(\mathrm{Hz})\end{array}$ & $\begin{array}{c}\text { Standart } \\
\text { Devisiasi } \\
(\mathrm{Hz})\end{array}$ \\
\hline $\begin{array}{l}\text { Epilepsi } \\
\text { Normal }\end{array}$ & 912 & -1765 & 203 & 527.862 \\
\hline $\begin{array}{l}\text { Epilepsi } \\
\text { Tidak } \\
\text { Normal } \\
\text { (Kejang) }\end{array}$ & 106 & -129 & 3 & 42.9292 \\
\hline
\end{tabular}

\section{Kesimpulan}

Dari hasil penelitian pada bab yang sudah dibahas sebelumnya dapat diambil kesimpulan bahwa :

1. Metode teknik sampling dengan mencari nilai maksimum, nilai minimum, nilai median, nilai standart daviasi dapat digunakan untuk mengekstraski ciri sinyal EEG untuk Gangguan Penyakit Epilepsi.

2. Pada penelitian ini peneliti menggunakan metode Teknik Sampling dan Backpropogation sebagai klasifikasinya.. Pada tahap pelatihan (training) menggunakan 80 data set dari masing-masing Set A dan Set E, sedangkan 
pada tahap pengujian (testing) menggunakan 100 data set. Penelitian ini menggunakan metode back- propogation (2-50-2) yaitu 2 input sinyal EEG, satu hidden layer dengan 20 unit dan dua target epilepsi dan non epilepsi . dari pengujian data tersebut didapat nilai akurasi sebesar $100 \%$.

\section{Daftar Pustaka :}

Anonym. 2002. Diagnosis Gangguan Jiwa Rujukan Ringkas dari PPDGJ-III. Editor oleh Rusli Salim. Jakarta
Ratnaprabaha R. Borhade, Dr. Manoj S.Nagmode 2014. EEG Signal Classification for Detection of epileptic Seizures By Extracting Various Features

Hindarto, Moch. Hariadi, Mauridhi Herry Purnomo, Identifikasi Sinyal Elektrode Enchepalo Graph Untuk Menggerakkan Kursor Menggunakan Teknik Sampling Dan Jaringan Syaraf Tiruan, 2011, Jurnal Kimiah Kursor, Vol 6, pp. 11-18. Departemen Epileptology, University of Bonn, Sigmund Freud-Strasse 25, 53105Bonn Jerman 